\title{
Trabalhadores em Saúde Mental: Relações entre Práticas Profissionais e Bem-estar Físico e Psicológico
}

Mental Health Workers:

Relationship between Professional Practice and the Physical and Psychological Well-being

Ionara Vieira

Moura Rabelo

Universidade Paulista

Ana Raquel Rosas Torres Universidade

Católica de Goiás
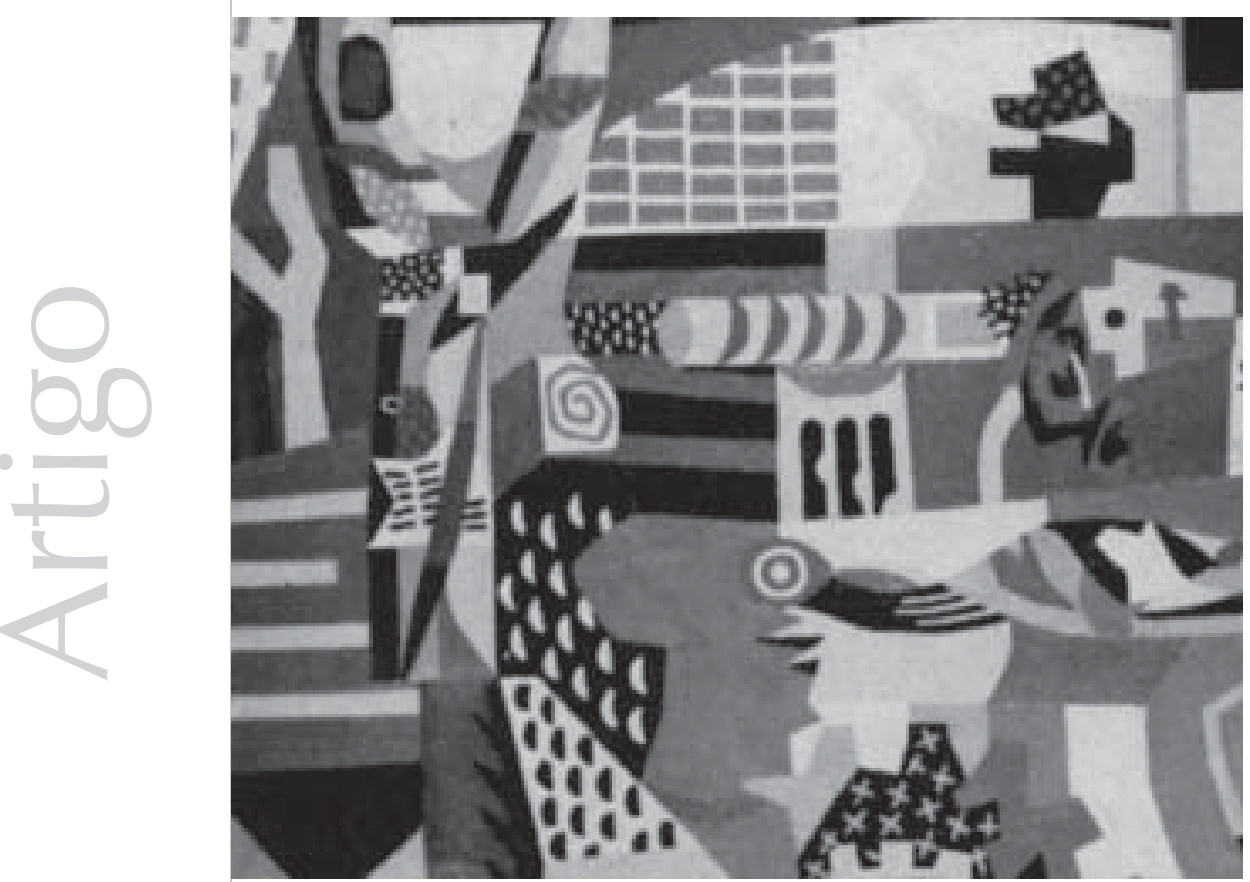


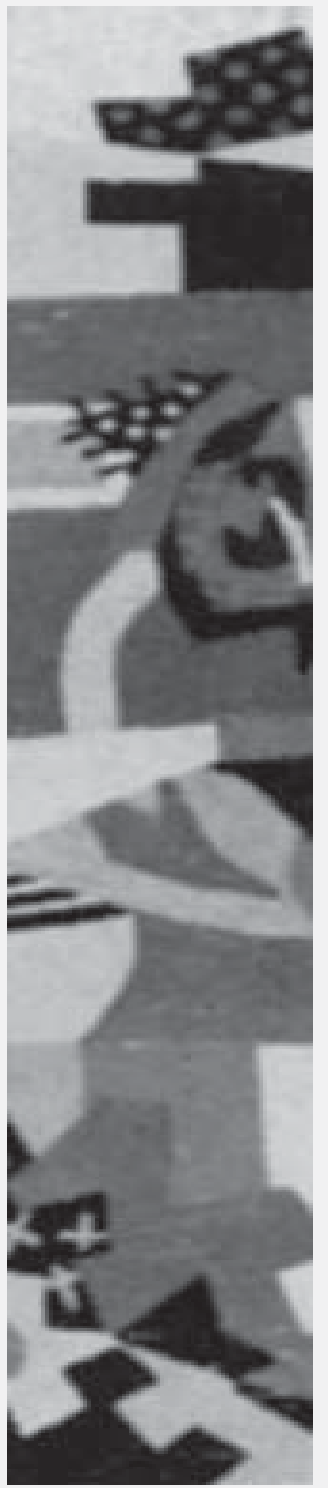

Resumo: Este estudo investiga o impacto da reforma psiquiátrica no bemestar físico e psicológico dos trabalhadores de saúde mental. Participaram 201 trabalhadores em saúde mental de hospitais psiquiátricos e serviços substitutivos de Goiânia. Foram analisadas as correlações entre adesão ao modelo teórico de atenção em saúde mental (biológico versus psicossocial), satisfação com atividades desempenhadas, local de trabalho, tempo de serviço e carga horária trabalhada com o bem-estar físico e psicológico dos trabalhadores. Constatou-se que os trabalhadores que mais aderem ao paradigma biológico e estão mais satisfeitos com as atividades desempenhadas são os que apresentam os níveis mais altos de bem-estar físico e psicológico. Esses resultados são discutidos enfatizando-se a importância desse tipo de análise para a consolidação da reforma psiquiátrica no Brasil.

Palavras-chave: reforma psiquiátrica, saúde e trabalho, saúde mental.

\begin{abstract}
This article investigates the impact of the psychiatric reform approaches on mental health workers' physical and psychological wellbeing. The participants were 201 mental health workers who were working in psychiatric hospitals and substitutive services in Goiânia. It was analyzed the correlation between the adhesion to the mental health theoretical model (biological versus psychosocial), workers' satisfaction with their professional activities, local of work (substitutive services versus psychiatric hospitals), time of work, working hours per day and the psychological and physical well-being. It was found that workers that were highly identified with the biological paradigm and were highly satisfied with their professional activities have presented the highest levels of well-being. These results are discussed emphasizing the importance of this kind of analyses for the consolidation of the psychiatric reform in Brazil.
\end{abstract}

Key words: psychiatric reform, health and work, mental health.

Sem dúvida, o desenvolvimento tecnológico que as sociedades modernas têm vivenciado nos últimos 50 anos tem facilitado enormemente a vida do trabalhador. No entanto, é inegável que esse mesmo desenvolvimento tecnológico tem contribuído para a progressiva exclusão dos trabalhadores do mercado de trabalho. Além disso, o desenvolvimento tecnológico tem contribuído também para aumentar a fragmentação das tarefas realizadas por aqueles que conseguem manter-se ativos. Trabalho alienado e desemprego figuram como estrelas da política neoliberal tão alardeada pelos especialistas em Economia, que insistem em culpabilizar a falta de qualificação como responsável pelos subempregos e mercado informal, sem que se pense no modelo hegemonicamente excludente que permeia as relações na sociedade capitalista.

Entender como o trabalho pode estar determinando características psicológicas e psicopatológicas de diferentes categorias 
No Brasil, encontrou-se prevalência de transtornos mentais entre trabalhadores ocupados semelhante aos indices mundiais e constatou-se também que esses transtornos são os responsáveis pelo maior tempo de afastamento do trabalho por doença Jardim profissionais é o objetivo de teóricos que realizam seus estudos com o apoio da Sociologia do trabalho, Psicologia organizacional, epidemiologia e psicopatologia do trabalho (Borges, 2001; Codo, 1999; Codo \& Sampaio, 1995; Jardim, 2001).

São poucos os dados que conseguem equacionar o sofrimento psíquico advindo do trabalho, mas estimam-se índices de 30\% de transtornos mentais menores e de $5 \%$ a $10 \%$ de transtornos mentais graves entre trabalhadores em todo o mundo (OMS, citado em Jardim, 2001).

No Brasil, encontrou-se prevalência de transtornos mentais entre trabalhadores ocupados semelhante aos índices mundiais e constatou-se também que esses transtornos são os responsáveis pelo maior tempo de afastamento do trabalho por doença (Jardim, 2001).

Mas, para Sampaio e Messias (2002), a epidemiologia psiquiátrica é bastante problemática porque apresenta intersecções fundamentais com processos socioeconômicos, políticos, culturais e ideológicos, e utiliza-se de medidas de critérios subjetivas, com áreas de atuação imprecisas e, principalmente, tem um "conflito fundamental entre um saber que deve expandir-se e uma prática especializada que deve se restringir" (Sampaio \& Messias, 2002, p.145).

No texto de Jacques (2002), é levantada a "doença dos nervos" (grifo da autora) como uma denominação freqüente que os trabalhadores brasileiros utilizam para identificar uma situação causada por ambientes de trabalho com muita tensão.

$\mathrm{Na}$ décima versão da Classificação Internacional de Doenças, publicada pela Organização Mundial da Saúde (1992), no quinto capítulo, as relações entre trabalho e doença mental não são claras. Jardim (2001) propõe, como pontos a serem observados na relação saúde mental-trabalho, quatro níveis: sociocultural, subjetivo, biológico e político, sendo que não se excluem, e sim, “(...) se entrelaçam, produzindo efeitos ao mesmo tempo singulares e coletivamente compartilhados (...)" (Jardim, 2001, p.140). Para Borges (2000), o funcionamento psíquico é regido pela busca do sentido/ prazer nas situações vividas, e se tal não se dá no trabalho, o Eu irá buscar estratégias defensivas ou mesmo ter-se-á a angústia como sintoma por excelência. Esse autor alerta para que se observe o contexto do trabalho, pois é a partir dele que se inscreve o sentido do sofrimento no trabalho.

Em outra vertente, encontramos estudos em Psicologia social e do trabalho que não enfatizam características individuais, mas a categoria identificação com a profissão como geradora de sofrimento, como o estudo de Ferreira e Torres (2001) com trabalhadores bancários afastados de suas atividades em função de distúrbios osteomusculares relacionados ao trabalho (DORT), cujos resultados demonstraram que os trabalhadores que mais se identificam com sua profissão são os que mais sofrem psicologicamente e apresentam menor disposição para mudar de profissão.

De acordo com Jardim (2001), há uma multiplicidade de sentidos no cotidiano do trabalho, que se apresentam como sintomas, síndromes e doenças, e ressalta: “(...) Não há uma clínica do sujeito e outra do trabalho. Há uma certa clínica, que leva em conta os sujeitos e o trabalho (...)" (Jardim, 2001, p.154).

Para Seligmann-Silva (2000), são muitos os estudos que tentam mapear a interface saúde mental e trabalho, mas tal é a diversidade de referenciais teóricos que ainda não se pode afirmar a existência de um único arcabouço teórico que explique as relações entre saúde mental e trabalho. 
Pitta (1999) realizou um estudo com 1.525 trabalhadores de um hospital geral na área central do município de São Paulo para avaliar as relações entre o processo de trabalho e o sofrimento psíquico. Os resultados demonstraram que $42,1 \%$ dos sujeitos pesquisados referiram-se a problemas de saúde nos últimos seis meses antes da pesquisa e, no screening (grifo da autora) psicopatológico, encontrou $57,7 \%$ de "suspeitos" (idem) com poliqueixas e $53,1 \%$ com transtornos mentais. Do quadro geral de problemas de saúde, excluídos os transtornos mentais, 20,6\% dos profissionais apresentaram patologias de provável etiologia psicossomática. Os que trabalham mais de doze horas foram os que mais apresentaram doenças somáticas, transtornos mentais, sintomas psicoemocionais e abuso de bebida alcoólica, sendo que os transtornos mentais apresentam maior prevalência no trabalho noturno.

Palácios (2000) afirma que não é a insalubridade vivenciada no ambiente de trabalho, mas a dificuldade em lidar com situações fora de seu controle é que gera a impotência, pois, para os médicos da emergência, seu trabalho é apenas uma parte do processo terapêutico, enquanto, para os auxiliares de enfermagem, é na enfermaria que eles se tornam meros executores de procedimentos, não tendo a possibilidade de compreender o todo. Já no estudo de Lara (1999), detectou-se que $40 \%$ dos profissionais de uma instituição psiquiátrica de Curitiba apresentaram escores elevados em esgotamento emocional, mas não se encontraram correlações positivas para o desenvolvimento da Síndrome de Burnout.

No estudo de Borges e Argolo (2002), foi analisado se componentes da motivação e do significado do trabalho estão relacionados a fatores do bem-estar psicológico entre bancários e profissionais de saúde. Um dos principais resultados encontrados foi que, quanto mais os profissionais de saúde percebem o desgaste e a desumanização no dia a dia de sua atuação e mais valorizam a justiça no trabalho, mais se sentem emocionalmente tensos e deprimidos.

Neste estudo, pretende-se investigar as relações entre saúde e trabalho, sem, contudo, ter a pretensão de esgotar esse tema. Entende-se que essas relações devem ser consideradas nas múltiplas facetas históricas que constroem o "trabalha-dor" ou mesmo o "trabalho-ardor", aspectos de um mesmo campo: dor, ardor, criatividade, tensão não devem ser polarizados, mas, sim, contemplados em seus encontros e desencontros.

Não separar artificialmente a vida, o trabalho e a doença (Jardim, 2001), eis os desafios que ora se colocam para o entendimento dos paradigmas que fundamentam a prática dos trabalhadores das instituições de saúde mental. Nesse cenário de turbulência das relações de trabalho, surge mais um dado: a reformulação das políticas de saúde mental no Brasil, com a implantação da reforma psiquiátrica. Neste momento, não só relações de trabalho são confrontadas, mas todas as relações de segregação da insanidade e tudo o mais que se caracteriza como diferente ou mesmo ineficiente à lógica de mercado neoliberal.

A proposta da reforma psiquiátrica surgiu em meio ao Movimento de Trabalhadores de Saúde Mental (Amarante, 1995), mas hoje é o eixo norteador da política de saúde mental do Ministério da Saúde (MINISTÉRIO DA SAÚDE, 2004). O compromisso com a desinstitucionalização da loucura e das práticas asilares que a encarceraram entre muros depende da atuação de profissionais que se coloquem à disposição para construírem novas possibilidades de encontro entre loucurasociedade.

Nesse momento, trabalhadores de saúde mental tornam-se peça fundamental num jogo em que a exclusão das diferenças sempre esteve à frente na partida. Qualificação, 
acompanhamento e supervisão contínuas são essenciais para que se garanta que o novo não termine por sucumbir à pressão do velho e acessível modo de tratamento manicomial. Este artigo é o resultado de uma pesquisa que teve como objetivo investigar o impacto da adesão aos diferentes paradigmas teóricos que norteiam a prática em saúde mental no bemestar físico e psicológico dos trabalhadores de saúde mental do município de Goiânia. Como eixo norteador deste estudo, tem-se o pressuposto que, no trabalho em saúde mental, permeiam conflitos que explicitam diferentes paradigmas, ideologia, lutas sociais, lutas entre categorias profissionais que se refletirão na saúde do trabalhador. Considerase também que o próprio lidar cotidiano com a loucura é fomentador de conflitos que podem interferir no bem-estar físico e psicológico do trabalhador em saúde mental. Essas idéias serão discutidas detalhadamente a seguir.

\section{Reflexões sobre a interface saúde mental e trabalho}

Desde as primeiras inovações propostas por Pinel, a psiquiatria tem como pressuposto que, para se conhecer a loucura, deve-se observar os sintomas, o que é imediato, simples e quantificável, para, então, detectar-se a complexidade da doença. Daí o isolamento como condição essencial para se configurar o saber médico, que o utiliza não só como terapêutica mas também como forma de proteção da sociedade contra os males que os alienados podem causar. Constrói-se, dessa forma, a possibilidade permanente da exclusão, na medida em que a sociedade toma a verdade da psiquiatria como hegemônica e passa a sintonizar loucura com periculosidade, negatividade e reclusão, concepção essa que tem sua origem na Idade Clássica (Foucault, 1972).

Será na Itália, com Franco Basaglia, e depois, com a psiquiatria democrática italiana, que se iniciará o projeto que irá confrontar, com maior ênfase, o paradigma da psiquiatria clássica. De acordo com Amarante (1995), esse movimento elege um novo objeto que não se refere mais à doença mental e não tem a pretensão de colocar nada em seu lugar. Pelo contrário, propõe a construção conjunta de um saber que tente melhor alcançar o sofrimento de alguém junto à comunidade em que vive, e, para tanto, não há mais um locus para tratamento. O hospital perde, então, seu sentido de existir.

A partir do movimento de trabalhadores de saúde mental, logo apoiado por usuários e familiares dos serviços de saúde mental, surge, no Brasil, a reforma psiquiátrica, com uma trajetória de transformações das ações em saúde mental que têm por objetivo a superação do paradigma da psiquiatria clássica.

O movimento antimanicomial, que, inicialmente, é fruto da luta por melhores condições de trabalho dos profissionais que atuam em saúde mental, passa a tomar novo formato com a participação de familiares e usuários dos serviços de saúde mental. A reforma psiquiátrica passa a ser pauta constante de discussões nos diversos níveis de Governo até que o Ministério da Saúde inicie o processo de regulamentação dos serviços substitutivos em saúde mental: CAPS (Centro de Atenção Psicossocial) e NAPS (Núcleo de Atenção Psicossocial), considerados sinônimos via Portaria 189, de 19 de novembro de 1991, e 224, de 29 de janeiro de 1992 (MINISTÉRIO DA SAÚDE, 2002), têm a função de responder à necessidade do sujeito e não mais ao sintoma, como no caso do paradigma clássico.

Dessa forma, percebe-se como a mobilização popular consegue colocar em ação as propostas da reforma psiquiátrica. O Estado passa a implantar novos modelos de assistência, via criação em lei e financiamento dessa rede de serviços substitutivos, que inclui hospital-dia, enfermaria psiquiátrica em hospital 
geral, lar abrigado, pensão protegida, centros de convivência e cooperativas de trabalho. No Brasil, tais serviços passaram de 03 unidades, em 1990, a 516 CAPS, em 2004, mas ainda persiste $90 \%$ dos gastos em saúde mental com internações psiquiátricas (MINISTÉRIO DA SAÚDE, 2004).

É com a certeza de que essa nova proposta não está dada, via lei ou mesmo por pura vontade, que Amarante (1995) ressalta a importância de se repensar, diariamente, as práticas dos serviços substitutivos, pois, só por serem externos, não significa que não correm o risco de funcionarem exatamente iguais aos manicômios.

Como referencial teórico para este estudo, utilizou-se Costa-Rosa (2000), que propõe dois paradigmas das práticas em saúde mental com base em quatro parâmetros: a definição de seus objetos e meios de intervenção; as formas de organização dos dispositivos institucionais; as modalidades de relacionamento com usuários e população e as implicações dos efeitos de suas práticas em termos jurídicos, teórico-técnicos e ideológicos. A partir desses parâmetros, propõe o modo asilar como paradigma das práticas dominantes e o modo psicossocial como o paradigma que tem por base as práticas da reforma psiquiátrica. Esse autor ressalta que utiliza a análise dos paradigmas tentando elaborá-los como: “(...) formas de metabolização dos pólos da contradição essencial no campo das práticas em saúde mental" (Costa-Rosa, 2000, p.165). O modo asilar, segundo Costa-Rosa (2000), caracteriza-se por organogramas verticais, divisão do trabalho centrado nas especialidades e uma relação dicotômica com a clientela, diferenciando sãos e loucos. Há uma ênfase nas condições orgânicas como desencadeantes do problema mental. Nesse paradigma, o tratamento medicamentoso é o eixo central da intervenção. Não há investimento na participação do usuário, visto a pouca consideração à subjetividade. Tendo o indivíduo como doente, o tratamento centrase nessa unidade deixando em segundo plano o contexto familiar e ambiental.
A equipe, no modo asilar, funciona como uma linha de montagem, tendo o saber psiquiátrico como primeira etapa a ser verificada, para só então passar a saberes considerados complementares, tais como os saberes da Enfermagem e Psicologia, entre outros. Mesmo que a equipe discuta os casos, a eficácia esperada no tratamento tem como ponto nevrálgico a química cerebral que permite a remissão dos sintomas. Esse modo asilar possibilita à população eleger a instituição como lugar próprio dos enfermos, tendo como conseqüência a adaptação ao status dominante da subjetividade capitalista.

Já o modo psicossocial tenta o exercício de modelos horizontais na organização institucional, tendo o saber interdisciplinar como fomentador do debate acerca do objeto. A divisão do trabalho tenta a superação radical do modelo fragmentador, originando uma nova interlocução com a clientela, propondo o exercício de práticas de intersubjetividade horizontal (Costa-Rosa, 2000).

Nessa perspectiva, há a concepção de um sujeito que sofre e que está inserido numa família e comunidade que são considerados agentes de mudanças. Dessa forma, todos participam como ferramentas terapêuticas. Não se fala mais na clínica do indivíduo, mas da situação vivida. Trabalho, lazer, psicoterapia, terapia ocupacional, atividades de reintegração sociocultural e medicação constituem o que se nomeia projeto terapêutico individualizado. Nesse cenário, indivíduo, família e comunidade são mobilizados como atores de seu próprio destino. Propõe-se o reposicionamento do sujeito diante dos conflitos vividos no continuum saúde-doença.

Costa-Rosa (2000) afirma que "é em razão da consideração de que a loucura não é um fenômeno exclusivamente individual, mas social, e como tal deverá ser metabolizada" (p. 154). Para tal metabolização, a equipe conta com a experimentação cotidiana de novas possibilidades, nas quais o modelo médico é "é em razão da consideração de que a loucura não é um fenômeno exclusivamente individual, mas social, e como tal deverá ser metabolizada"

Costa-Rosa 
superado por um modelo que busca as múltiplas determinações do sofrimento mental. O modo asilar de Costa-Rosa (2000), que enfatiza fatores orgânicos como fundamentais nos problemas mentais, passa a ser denominado, neste estudo, paradigma biológico. Já o modo psicossocial, que inaugura novas relações com a loucura, é chamado de paradigma psicossocial.

\section{Método}

Ressalta-se que este estudo é correlacional, ou seja, analisam-se as correlações entre as variáveis antecedentes com a variável critério, não pressupondo relações de causalidade.

A partir da revisão teórica sobre trabalho, saúde mental e reforma psiquiátrica, identificaramse dois paradigmas que embasam os modos de atenção em saúde mental: paradigma biológico e paradigma psicossocial. Tais paradigmas serão tratados como atitudes em saúde mental e, junto à satisfação com as atividades desempenhadas, o tipo de local de trabalho, tempo de serviço e carga horária trabalhada, serão considerados variáveis antecedentes. Como variável critério, escolheu-se o bem-estar físico e psicológico.

\section{Amostra e procedimentos}

Considerando como serviços representantes da psiquiatria tradicional as clínicas psiquiátricas e como serviços substitutivos em saúde mental as unidades públicas especializadas em saúde mental, optou-se por ter, como participantes deste estudo, trabalhadores desses dois tipos de serviço acima citados. No entanto, essa é apenas uma divisão didática, pois acredita-se que não seja apenas o locus de trabalho que irá diferenciá-los como representantes da psiquiatria tradicional ou da reforma psiquiátrica, mas, sim, as opiniões e práticas profissionais concretas.

Ressalta-se que o paradigma biológico, até então hegemônico, legitima o funcionamento das clínicas psiquiátricas, sendo que a reforma psiquiátrica fundamenta-se no paradigma psicossocial e, portanto, tem como locus para tratamento os serviços substitutivos de atenção em saúde mental. Tal polarização teórica, no entanto, não impede que, nos dois tipos de serviços, convivam práticas biológicas e psicossociais, daí a relevância deste estudo em tentar captar as práticas de saúde mental existentes em ambos os contextos.

Com a autorização da Coordenação de Saúde Mental da Secretaria Municipal de Saúde, foram entrevistados profissionais dos seis serviços de atenção em saúde mental da Rede Básica de Saúde de Goiânia, também conhecidos como serviços substitutivos em saúde mental. Ressalta-se que, na rede pública, só existiam, até o momento da pesquisa, esses seis serviços especializados em saúde mental.

Das nove clínicas psiquiátricas existentes em Goiânia, foram contatadas seis instituições. Decidiu-se por pesquisar seis clínicas para manter um número equivalente com o número de serviços substitutivos existentes, no caso, seis unidades.

Ao todo, foram entrevistados 201 profissionais que trabalham em serviços de saúde mental de Goiânia, sendo que, para análise dos dados, foram considerados 180 casos válidos. Os questionários foram aplicados, individualmente, no local e horário de trabalho dos profissionais, com tempo médio de 30 minutos para respondê-lo.

\section{Instrumento}

O questionário utilizado era formado por duas escalas:

- Escala de bem-estar físico e psicológico: adaptada da escala utilizada nos estudos de Ferreira e Torres (2001) e Lima Paula e Torres (2001), composta de trinta e dois itens em formato Likert, variando de 1 (nunca percebe 
esta situação) a 7 (sempre percebe esta situação). Essa escala foi desenvolvida para o Centro Nacional de Estatística sobre Saúde, nos Estados Unidos da América, por Fazio (1977). Como exemplo desses itens, temos: você tem estado nervoso?; você tem se sentido triste, desencorajado(a), desesperançado(a) ou tido muitos problemas que lhe trazem preocupação?

Escala de atitudes em saúde mental: desenvolvida pelo Grupo de Pesquisa em Processos Grupais a partir de um estudo piloto com estudantes de uma universidade privada de Goiânia. A escala é composta por 26 itens em formato Likert, variando de 1 (discorda plenamente com relação à afirmação) a 7 (concorda plenamente com relação à afirmação). Utilizaram-se treze itens que configuravam o paradigma biológico e treze itens com características das práticas do paradigma psicossocial. Como exemplo dos itens, tem-se: o doente mental deve ser isolado quando fica agressivo fisicamente (paradigma biológico); os vínculos sociais podem tratar um paciente psiquiátrico (paradigma psicossocial).

Além dessas escalas, o questionário também continha:

Uma questão sobre o grau de satisfação com relação às atividades desenvolvidas pelo profissional, variando de zero a dez, sendo que o valor dez representa estar extremamente satisfeito.

Três questões sobre local de trabalho, tempo de serviço e carga horária trabalhada.

\section{Resultados}

O primeiro passo foi iniciar a investigação das estruturas subjacentes às escalas Likert utilizadas. Para tanto, foram feitas duas análises dos componentes principais, com rotação
Varimax, uma com a escala de atitudes em saúde mental e outra com a escala de bemestar físico e psicológico. Em ambas, foram consideradas as cargas fatoriais superiores a 0,35 .

Os resultados da escala de atitudes permitiram visualizar uma estrutura axiológica formada por dois fatores. No primeiro fator, encontram-se os itens que caracterizam o paradigma biológico que legitimam a doença, a internação e interdição do doente mental. O segundo fator é composto por itens que representam o paradigma psicossocial, que trata da reinserção social do sujeito que apresenta sofrimento psíquico através de ações de resgate da cidadania e vínculo com a família. Esses fatores explicavam 33\% da variância dos itens, com coeficiente de fidedignidade (alfa de Cronbach) de 0,86 para o paradigma biológico e 0,76 para o paradigma psicossocial. Os níveis de adesão a cada uma dessas escalas serão analisados posteriormente.

Com relação à escala de bem-estar físico e psicológico, encontrou-se um único fator com $27 \%$ da variância dos itens. O coeficiente de fidedignidade (alfa de Cronbach) foi de 0,89. Esses resultados são semelhantes aos encontrados por Ferreira e Torres (2001) e Lima Paula e Torres (2001). Essa escala teve média igual a 5,4 e desvio padrão de 0,82 , mostrando que, no geral, os trabalhadores não têm queixas sobre seu bem-estar.

Foi realizada regressão múltipla (Tabela 1) pelo método stepwise, tendo como variável critério o bem-estar dos trabalhadores em saúde mental e como variáveis antecedentes os níveis de adesão ao paradigma biológico e ao paradigma psicossocial, a satisfação com as atividades desempenhadas, o tipo de local de trabalho, o tempo de serviço e a carga horária trabalhada. 
Tabela1. Regressão múltipla pelo método stepwise, correlacionando bem-estar físico e psicológico com adesão ao paradigma biológico, paradigma psicossocial, satisfação com as atividades desempenhadas, local de trabalho, tempo de serviço e carga horária trabalhada.

\begin{tabular}{|c|c|c|c|}
\hline & \multicolumn{3}{|c|}{ Bem-estar físico e psicológico } \\
\hline & Beta & $\mathrm{T}$ & $\mathrm{p}<$ \\
\hline Paradigma Biológico & 0,143 & 2,074 & 0,05 \\
\hline Paradigma Psicossocial & 0,007 & 0,076 & n.s. \\
\hline Satisfação com atividades desempenhadas & 0,363 & 5,247 & 0,001 \\
\hline Local de trabalho & 0,000 & 0,000 & n.s. \\
\hline Tempo de serviço & 0,062 & 0,878 & n.s. \\
\hline Carga horária trabalhada & $-0,073$ & $-1,022$ & n.s. \\
\hline Coeficiente de regressão & \multicolumn{3}{|c|}{$R=0,406$} \\
\hline Variância explicada & \multicolumn{3}{|c|}{$\mathrm{R}^{2}=0,165 ; \mathrm{R}^{2}$ Ajustado $=0,155$} \\
\hline Significância do modelo & \multicolumn{3}{|c|}{$F(2 / 177)=17,441 ; p<0,001$} \\
\hline
\end{tabular}

Para a inclusão da variável nominal local de trabalho, foram construídas duas variáveis, onde: "Clínica $=1$ e serviço substitutivo=2".

Ao avaliar a Tabela 1, percebe-se que os sujeitos que mais apresentam adesão ao paradigma biológico e sentem-se satisfeitos com as atividades que desempenham em seu local de trabalho são aqueles que mais apresentam bem-estar físico e psicológico, sendo que nenhuma das outras variáveis foi significativa.

Ao realizar Teste-t comparando adesões ao paradigma biológico e psicossocial de acordo com o tipo de instituição (Tabela 2), percebe-se maior afinidade pelo paradigma psicossocial em ambos os serviços: uma média de 5,37 no serviço substitutivo e de 4,85 no hospital psiquiátrico.

Tabela 2 - Médias e teste estatístico dos paradigmas biológico e psicossocial por local de trabalho.

\begin{tabular}{|l|l|l|l|l|l|l|l|l|} 
& \multicolumn{2}{l}{$\begin{array}{l}\text { Serviço } \\
\text { Substitutivo }\end{array}$} & \multicolumn{2}{l|}{$\begin{array}{l}\text { Hospital } \\
\text { Psiquiátrico }\end{array}$} & \multicolumn{3}{c|}{$\begin{array}{l}\text { Teste } \\
\text { Estatístico }\end{array}$} \\
& M & DP & M & DP & Teste t & gl & p $<$ \\
\hline Paradigma Biológico & 2,79 & 0,87 & 3,77 & 0,99 & $-6,341$ & 150 & 0,001 \\
\hline Paradigma Psicossocial & 5,37 & 0,81 & 4,85 & 0,83 & 3,834 & 152 & 0,001 \\
\hline
\end{tabular}

Na figura 1, a seguir, percebe-se a presença de ambos os paradigmas tanto no serviço substitutivo como no hospital psiquiátrico. Porém, o paradigma psicossocial é o que mais aparece nos dois locais de trabalho.

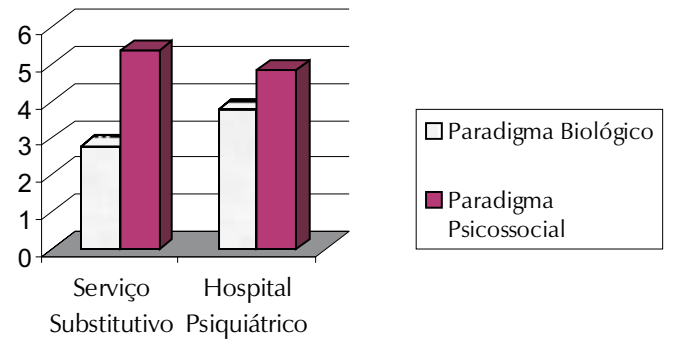

Figura 1 - Representação das médias de adesão ao paradigma biológico e psicossocial de acordo com o local de trabalho. 


\section{Discussão e conclusões}

A trajetória da reforma psiquiátrica tem sido cartografada por vários teóricos (Amarante, 1995; Bezerra \& Amarante, 1992; Costa, 1989; Tundis \& Costa, 2000), sendo interessante a perspectiva de que a luta pela desinstitucionalização dos saberes e práticas que encarceraram a loucura não é dada linearmente, ou seja, não é tão óbvia como uma simples diferenciação entre certo e errado. A complexidade das relações estabelecidas entre sociedade e loucura transforma-se a cada tentativa de rompimento com modelos manicomiais. Talvez se explique a longevidade do modelo asilar por sua incrível capacidade plástica de incorporar os anseios da sociedade.

Neste estudo, tentou-se compreender a experiência daqueles que fazem a ponte entre loucura e comunidade e, portanto, estão de posse de discursos que, disfarçados ou não na forma de saberes científicos, terminam por representar não só o grupo de profissionais da área da saúde mas também a sociedade em que estão inseridos.

De acordo com os pressupostos da reforma psiquiátrica, o campo da saúde mental é um espaço bem mais amplo que apenas o saber/ fazer que o paradigma biológico legitimou. É um campo de lutas onde trabalhador/usuário/ sociedade constroem novas formas de relação com a loucura/diferença. Tal construção requer que ao menos o trabalhador esteja mais capacitado para negociar novos contratos sociais, mais capacitado nos aspectos teórico, físico, psíquico e social para desencadear novas relações entre sociedade e saúde mental.

Neste estudo, avaliou-se o impacto da adesão aos dois paradigmas que vêm historicamente norteando as práticas em saúde mental, na saúde física e psicológica dos trabalhadores de serviços de saúde mental do município de Goiânia.
Os resultados da regressão múltipla mostraram que os trabalhadores que mais aderem ao paradigma biológico são os que mais apresentam bem-estar. Outra variável que se correlacionou positivamente com o bem-estar foi a satisfação com as atividades desenvolvidas, ou seja, quanto maior a satisfação com as atividades no trabalho maior o bem-estar do trabalhador.

É interessante pontuar que a adesão ao paradigma biológico não significa que são trabalhadores que estão atuando em hospitais psiquiátricos, pois não se trabalhou com a suposição de que seria o local de trabalho que representaria as práticas em saúde mental, mesmo porque os resultados demonstram a convivência dos dois paradigmas em todos os locais pesquisados. Isso pode significar que estamos vivenciando um momento de transição, onde o modelo biológico não foi completamente abandonado nem tampouco o modelo psicossocial conseguiu ser ainda definitivamente implantado.

Ressalta-se que os níveis de bem-estar físico e psicológico são idênticos nos dois ambientes de trabalho: clínica psiquiátrica e serviço substitutivo. Diante dessa reflexão, podemos começar a entender a relação entre a adesão ao paradigma biológico e níveis mais elevados de bem-estar físico e psicológico.

O saber conhecido e legitimado por séculos talvez fundamente a crença que "essa é a melhor forma para tratar a loucura", dando segurança ao trabalhador para lidar com o novo e desconhecido, ou seja, em momentos de transição, as práticas conhecidas vão dar segurança ao profissional. No entanto, podese inferir que o discurso contemporâneo das idéias da reforma psiquiátrica que ressaltam a reinserção social faz com que essas práticas seculares sejam vistas como obsoletas. As práticas do paradigma biológico passam, então, a não serem mais defendidas publicamente, mas, de forma sutil, continuam a fazer parte 
da prática diária dos profissionais de saúde mental. Estaríamos, então, diante de uma situação onde existiria o divórcio entre o discurso oficial e as práticas concretas desenvolvidas nos serviços de atenção à saúde mental.

Este estudo não consegue responder o que fomenta essa relação. Pode-se fazer suposições para futuros estudos: atuar em um modelo excludente e segregador reafirma a realidade em que vivemos trazendo bemestar? Interagir numa relação vertical gera mais bem-estar? A objetivação da loucura propicia meios mais concretos e, portanto, facilitadores ao bem-estar do trabalhador?

Outra reflexão que pode ser feita com relação ao paradigma biológico é que, ao eleger como determinante para o sofrimento mental a objetivação da doença, retira do trabalhador a responsabilidade sobre esse usuário, já que, com relação aos aspectos físicos, a medicação pode ser considerada um fator de peso para intervir sobre a doença. Tal pensamento pode fomentar uma relação que traga bem-estar na medida em que o trabalhador não necessite responsabilizar-se por mais nada. Aspectos psíquicos e sociais são esquecidos a favor do físico que está sendo medicalizado.
Na regressão múltipla, não houve correlação negativa entre carga horária trabalhada e bem-estar físico e psicológico. Supõe-se que tal resultado se deva ao fato de os profissionais conhecerem sinais e sintomas indicativos dos transtornos de saúde mental e os negarem para justificar sua identidade profissional. Esse é um ponto que merece ser aprofundado em futuros estudos, talvez com entrevistas em profundidade que tentem apreender a identidade construída por trabalhadores de saúde mental neste momento de transição.

Por último, é importante ressaltar as limitações do instrumento utilizado neste estudo, que necessita de futuras reformulações, pois não só o conhecimento prático de psicopatologia mas também um contexto social que exige eficiência, individualismo, competição, competência técnica e afetiva cobram do trabalhador um perfil profissional que não admite falhas. Daí a importância de novos estudos que tentem explicar a complexidade do contexto daqueles que trabalham em saúde mental e, portanto, cobram de si que se coloquem no pólo saudável da antinomia saúdedoença. 


\section{Ionara Vieira Moura Rabelo}

Psicóloga, Mestre em Psicologia pela Universidade Católica de Goiás, professora-adjunta do Instituto de

Ciências Humanas da Universidade Paulista (Campus Goiânia), psicóloga do CAPS Beija-flor da Secretaria

Municipal de Saúde de Goiânia. Universidade Católica de Goiás. Departamento de Psicologia -

Av. Universitária, 1440, Setor Universitário - Goiânia -Goiás - 74605-010 E-mail: ivmr@terra.com.br

Ana Raquel Rosas Torres

Psicóloga, Doutora em Psicologia pela University of Kent at Canterbury (Reino Unido), professora titular do

Departamento de Psicologia da Universidade Católica de Goiás, professora do Mestrado em Psicologia da Universidade Católica de Goiás.

Grupo de Pesquisa em Processos Grupais Caixa Postal 12918,Goiânia, Goiás CEP 74643-970 Tel.: (62) 2257447 E-mail: ar.torres@ucg.br

AMARANTE, P. (org.). Loucos pela Vida: a Trajetória da Reforma Psiquiátrica no Brasil. Rio de Janeiro: Editora Fiocruz, 1995.

BEZERRA, B. \& AMARANTE, P.D.C. (orgs.). Psiquiatria sem Hospício: Contribuições ao Estudo da Reforma Psiquiátrica. Rio de Janeiro: Relume-Dumará, 1992.

BORGES, L. H. Trabalho em Processos Repetitivos: Sociabilidade, Sofrimento Psíquico e Lesões por Esforços Repetitivos (L.E.R.). In Silva, M. G. R., \& Jardim, S. R. (eds.). Organização do Trabalho e Saúde Mental (4⿳亠口了 ed.). Rio de Janeiro: UFRJ/IPUB, nº 2, 2000, pp.67-80.

BORGES, L. H. As Lesões por Esforços Repetitivos (L.E.R.) como Índice do Mal-estar no Mundo do Trabalho. In Borges, L.H., Moulin, M.G.B., \& Araujo, M.D. (orgs.) Organização do Trabalho e Saúde: Múltiplas Relações. Vitória: EDUFES, 2001, pp.157-174.

BORGES, L. O., \& ARGOLO, J.C.T. Estratégias Organizacionais na Promoção de Saúde Mental do Indivíduo Podem ser Eficazes? In Jacques, M.G., \& Codo, W. (orgs.). Saúde Mental \& Trabalho: Leituras. Petrópolis: Vozes, 2002, pp. 271-295.

CODO, W. (coord.). Educação: Carinho e Trabalho. (3ª ed.). Petrópolis: Vozes, 1999.

CODO, W., \& SAMPAIO, J. J. C. (orgs.). Sofrimento Psíquico nas Organizações: Saúde Mental e Trabalho. Petrópolis: Vozes, 1995. COSTA- ROSA, A. O Modo Psicossocial: um Paradigma das Práticas Substitutivas ao Modo Asilar. In Amarante, P. (coord.). Ensaios: Subjetividade, Saúde Mental, Sociedade. Rio de Janeiro: Editora Fiocruz, 2000.

COSTA, J.F. História da Psiquiatria no Brasil_um Corte Ideológico (4를 ed.). Rio de Janeiro: Xenon, 1989.

FAZIO, A. F. A Concurrent Validational Study of the NCHS General Well-Being Schedule (Dept. of H.E.W. Pupl. HRA- 78 - 1347) Hyattsville, MD: National Center for Health Statistics, 1977.

FERREIRA, M.C.P., \& TORRES, A.R.. Bancários Portadores de Distúrbios Osteomusculares Relacionados ao Trabalho e Identidade Profissional. Estudos - Vida e Saúde, v. 28, no 4. Goiânia: Revista de Universidade Católica de Goiás, 2001, pp.749-781.

FOUCAULT, M. História da Loucura na Idade Clássica (6ํee ed.). São Paulo: Ed. Perspectiva, 1972.
JACQUES, M.G. "Doença dos Nervos": uma Expressão da Relação entre Saúde/Doença mental. In Jacques, M.G., \& Codo, W. (orgs.). Saúde Mental \& Trabalho: Leituras. Petrópolis: Vozes, 2002, pp.98111.

JARDIM, S. R. Trabalho e Doença Mental. In Borges, L. H., Moulin, M. G. B., \& Araújo, M. D. (orgs.). Organização do Trabalho e Saúde Mental: Múltiplas Relações. Vitória: EDUFES, 2001, pp. 137-156.

LARA, S. A Síndrome de Burnout em Profissionais da Área de Saúde Mental. Monografia de Pós-Graduação em Saúde do Trabalho. Curitiba, Paraná: Universidade Federal do Paraná, Setor de Ciências da Saúde, 1999.

LIMA PAULA, M.A.P. \& TORRES, A.R. Identidade Social e o Envolvimento em Acidentes de Trânsito. Estudos_Vida e Saúde, v. 28, no 4. Goiânia: Revista de Universidade Católica de Goiás, 2001, pp. 717-747.

MINISTÉRIO DA SAÚDE. Legislação em Saúde Mental (3ª̣ ed.). Brasília: Série Legislação em Saúde, 2002.

MINISTÉRIO DA SAÚDE. Saúde Mental no SUS: os Centros de Atenção Psicossocial. Ministério da Saúde, Secretaria de Atenção à Saúde, Departamento de Ações Programáticas Estratégicas. Brasília: Ministério da Saúde, 2004.

ORGANIZAÇÃO MUNDIAL DE SAÚDE. The ICD-10 Classification of Mental and Behavioural Disorders: Clinical Description and Diagnostic Guidelines. Genebra: Organização Mundial da Saúde, 1992.

PALÁCIOS, M. A Saúde Mental de quem Trabalha em Saúde: o Caso de um Hospital Geral do Rio de Janeiro. In Silva, M. G. R., \& Jardim, S. R.(eds.). Organização do Trabalho e Saúde Mental (4⿳亠口冋 ed.). Rio de Janeiro: UFRJ/IPUB, n. 2, 2000, pp.52-66.

PITTA, A. M. F. Hospital: Dor e Morte como Ofício (3ํㅡ ed.). São Paulo: Hucitec, 1999.

SAMPAIO, J.J.C., \&MESSIAS, E.L.M. A Epidemiologia em Saúde Mental e Trabalho. In Jacques, M.G., \& Codo, W. (orgs.). Saúde Mental \& Trabalho: Leituras. Petrópolis: Vozes, 2002, pp. 143-172.

SELIGMANN-SILVA, E. Saúde Mental e Trabalho. In Tundis, S.A., \& Costa, N.R. (orgs.). Cidadania e Loucura Políticas de Saúde Mental no Brasil (6 $6^{\underline{a}}$ ed.). Petrópolis: Vozes, 2000, pp. 217-288.

TUNDIS, S.A., \& COSTA, N.R. (orgs.). Cidadania e Loucura: Políticas de Saúde Mental no Brasil (6ª ed.). Petrópolis: Vozes, 2000.

\section{Referências}

